\title{
BMJ Open The association between submarine service and multimorbidity: a cross- sectional study of Korean naval personnel
}

\author{
Jihun Kang, ${ }^{1}$ Yun-Mi Song ${ }^{2}$
}

To cite: Kang J, Song Y-M. The association between submarine service and multimorbidity: a cross-sectional study of Korean naval personnel. BMJ Open 2017;7:e017776. doi:10.1136/ bmjopen-2017-017776

- Prepublication history and additional material for this paper are available online. To view these files, please visit the journal online (http://dx.doi. org/10.1136/bmjopen-2017017776).

Received 16 May 2017 Revised 10 August 2017 Accepted 18 August 2017
CrossMark

${ }^{1}$ Department of Family Medicine, Kosin University Gospel Hospital, Kosin University College of Medicine, Busan, Korea

${ }^{2}$ Department of Family Medicine, Samsung Medical Center, Sungkyunkwan University School of Medicine, Seoul, Korea

Correspondence to

Dr Yun-Mi Song;

yunmisong@skku.edu

\section{ABSTRACT}

Objective We aimed to estimate the prevalence of multimorbidity ( $\geq 2$ chronic health problems) among Korean submariners and to evaluate the association between submarine service and multimorbidity and disease burden. Study design and setting This cross-sectional study included 590 naval personnel who visited a Korean primary care clinic during 2014-2015. Data regarding general characteristics and morbidities were collected from medical records, and disease burden was assessed using the Cumulative IIIness Rating Scale (CIRS). Multiple logistic regression analysis was used to evaluate the association between submarine service and multimorbidity and disease burden.

Results The prevalence of multimorbidity was $11.7 \%$ among 180 non-submariners and $32.2 \%$ among 410 submariners. The prevalence of multimorbidity and the CIRS scores gradually increased with age. Submarine service was associated with higher risk of multimorbidity and disease burden compared with non-submarine service even after adjusting for age, alcohol consumption, smoking status and naval rank. However, a dose-response relationship was not evident between the duration of submarine service and the risk of multimorbidity as well as high disease burden.

Conclusions Submarine service was significantly associated with a higher risk of multimorbidity and greater disease burden than non-submarine service. This finding suggests that multidimensional and holistic healthcare approaches are needed for submariners.

\section{INTRODUCTION}

Multimorbidity (the co-existence of $\geq 2$ longterm diseases or medical conditions in one person) is associated with increased medical expenditure,${ }^{1}$ decreased quality of life $^{2}$ and higher mortality. ${ }^{3}$ With increasing life expectancy and an ageing population, ${ }^{4}$ multimorbidity has become an important public health issue $^{5}$ because elderly people are likely to have multiple co-existing medical conditions. Therefore, most multimorbidity research has been performed among older populations, ${ }^{36}$ although multimorbidity is not just an issue for elderly people. ${ }^{7}$ A recent study found that

\section{Strengths and limitations of this study}

This is the first study to evaluate multimorbidity as well as disease burden in submariners.

- The cross-sectional design precludes any conclusions regarding the direction of causality in the relationship between submarine service and multimorbidity.

- The specificity of our study population, Korean submariners, limits the generalisation of our findings to other populations.

$>50 \%$ of people with multiple medical conditions were $<65$ years old, ${ }^{8}$ which indicates that multimorbidity should be investigated in populations with a broader age range. ${ }^{9}$

Military personnel are often relatively young people who undergo physical training and military drilling before deployment. Among military personnel, submariners are a unique population because they complete a specialised selection process and training to ensure that they can perform their demanding duties. Thus, submariners are considered a relatively healthy group at the time of their recruitment. ${ }^{10}$ However, submariners are concurrently exposed to various environmental risk factors that can affect their health status, such as their confined work environment, physical inactivity, excessive caloric intake, circadian disruption and isolation from family during deployment. ${ }^{11-13}$ A few studies evaluating the effects of these occupational risk factors on submariners' health status have reported controversial findings. A Norwegian study revealed that submariners had increased risk of bladder cancer and non-melanoma skin cancer. ${ }^{14}$ Similarly, a German study revealed that submariners had a higher rate of Helicobacter pylori infection compared with other naval personnel. ${ }^{15}$ On the other hand, a British study revealed that submarine service was not associated with 
increased risk of mortality or specific diseases. ${ }^{16}$ Moreover, little is known about whether submarine service is associated with multimorbidity. Therefore, this study aimed to estimate the prevalence of multimorbidity among Korean submariners and to evaluate the association between submarine service and multimorbidity and disease burden by comparing submariners and non-submarine naval personnel.

\section{METHODS AND MATERIALS \\ Study design and participants}

This cross-sectional study analysed data from the medical records of naval personnel who visited a primary care facility at the military base in Jinhae (Republic of Korea) between April 2014 and March 2015. Of the 1004 men who visited the clinic, we excluded 332 men who had a temporary service commission (conscripted individuals who were not eligible for submarine service) and 82 men with missing information regarding their sociodemographic characteristics $(n=15)$ or disease status $(n=67)$. Thus, 590 permanently commissioned naval personnel who volunteered for professional naval service were ultimately included in this study. We defined submariner as a person who had completed submarine training courses and worked in a submarine for $\geq 6$ months, and categorised the subjects as either submariners ( 410 men) or non-submariners (180 men).

The study's protocol complied with the STROBE guidelines. In addition, the protocol was approved and the requirement for informed consent was waived by the institutional review board of the Armed Forces Medical Command in Seongnam, South Korea (AFMC-15088-IRB-15-068).

\section{Data collection}

The subjects' sociodemographic data (age, years of submarine service and naval rank), anthropometric data (height and weight) and health behaviours (smoking status and alcohol consumption) were obtained by reviewing their medical records. Current smokers were defined as individuals who had smoked $>100$ cigarettes during their life and were currently smoking. Self-reporting was used to identify individuals who consumed alcohol. Body mass index (BMI, $\mathrm{kg} / \mathrm{m}^{2}$ ) was calculated as weight divided by height squared, and we defined obesity as a BMI of $\geq 25 \mathrm{~kg} / \mathrm{m}^{2}$, based on the definition for the Korean population. ${ }^{17}$

We identified co-existing chronic health problems in several ways. First, using a self-administered questionnaire, we asked the study subjects to answer 'yes' or 'no' to each question regarding whether they had experienced or had received treatment for the chronic conditions: diabetes, chronic obstructive pulmonary disorder, asthma, hypertension, dyslipidemia, heart disease (congestive heart failure and ischaemic heart disease), stroke, gastro-oesophageal reflux, sleep apnoea, arthritis, kidney disease or psychological disorders. Next, an additional physician-led examination was carried out to identify any unreported conditions. In addition, we reviewed the medical records of each study subject. We reviewed medical records from the date of implementation of the electronic medical record system (2013) onwards, and data were extracted and medical conditions classified using disease codes from the 10th revision of the International Statistical Classification of Diseases and Health Problems. The presence of multimorbidity ( $\geq 2$ chronic medical conditions) was evaluated by counting the number of chronic health conditions that each subject had.

We estimated disease burdens based on the illnesses and their severities using the Cumulative Illness Rating Scale (CIRS). ${ }^{18}$ This tool assesses symptoms in 14 organ domains (cardiac; vascular; haematological; respiratory; eye, ear, nose and throat; upper gastrointestinal tract; lower gastrointestinal tract; hepatic and pancreatic; renal; genitourinary; musculoskeletal and tegumental; neurological; endocrine, metabolic, breast; and psychiatric). The CIRS was originally developed by Linn et $a l^{19}$ to assess chronic medical problems in a comprehensive manner, and was subsequently revised by Miller $e t a l^{20}$ to measure common morbidities among elderly patients. This tool was later modified by Hudon $e t a l^{18}$ to estimate multimorbidity in the primary care setting, and was found to be a reliable and valid tool. ${ }^{21} 22$ The CIRS score for each organ system ranges from 0 (no problems affecting that system) to 4 (extremely severe problems), and the total CIRS score is calculated by adding the scores for all 14 organ domains (range: $0-56$ ). If a person currently smokes or has a high BMI $\left(\geq 25 \mathrm{~kg} / \mathrm{m}^{2}\right)$, then the person is considered to have disease burden in the respiratory and metabolic systems, respectively. The total CIRS score has a left-skewed distribution because it is very rare for a person to have severe medical conditions in every organ system.

\section{Statistical analysis}

The demographic characteristics, distributions of chronic health problems and CIRS scores were compared between submariners and non-submariners using the $\mathrm{X}^{2}$ test and t-test, as appropriate. We also compared the distributions of chronic health problems and CIRS scores for three age strata ( $<30$ years, $30-39$ years and $\geq 40$ years) because the age distributions were significantly different between the submariners and non-submariners. There is no standardised cut-off value for high disease burden based on CIRS score, and we arbitrarily defined subjects in the upper tertile of CIRS scores $(\geq 3)$ as having high disease burden. We also evaluated the associations of submarine service with multimorbidity and high disease burden using multiple logistic regression analysis after adjusting for age, alcohol consumption, smoking status and naval rank (reference group: non-submariners with 0 years of submarine service). However, we did not include smoking status as a covariate in the model for disease burden, because it is a component of the CIRS score. All statistical analyses were performed using PASW Statistics software 
Table 1 General and clinical characteristics of study subjects

\begin{tabular}{|c|c|c|c|c|}
\hline & Overall $(n=590)$ & Non-submariner $(n=180)$ & Submariner $(n=410)$ & p Value* \\
\hline Age, years, mean (SD) & $33.2(8.5)$ & $31.2(9.9)$ & $34.1(7.7)$ & $<0.001$ \\
\hline Height, cm & $173.8(0.1)$ & $173.4(0.1)$ & $174.0(0.1)$ & 0.189 \\
\hline$\geq 25 \mathrm{~kg} / \mathrm{m}^{2}, \mathrm{~N}(\%)$ & 267 (45.3) & $63(35.0)$ & $204(49.8)$ & 0.001 \\
\hline $18.5-24.9 \mathrm{~kg} / \mathrm{m}^{2}, \mathrm{~N}(\%)$ & $322(54.6)$ & $116(64.4)$ & $206(50.2)$ & \\
\hline Alcohol consumption, $\mathrm{N}(\%)$ & $487(82.5)$ & $152(84.4)$ & $335(81.7)$ & 0.420 \\
\hline Current smoker, N(\%) & 277 (46.9) & $68(37.8)$ & $209(51.0)$ & 0.003 \\
\hline Job ranking, $\mathrm{N}(\%)$ & & & & $<0.001$ \\
\hline Officer & $103(17.5)$ & $31(17.2)$ & $72(17.6)$ & \\
\hline Petty officer & $465(78.8)$ & $127(70.6)$ & $338(82.4)$ & \\
\hline
\end{tabular}

* $p$ Value was obtained from the t-test for continuous variables and $\chi^{2}$ test for categorical variables.

$\mathrm{N}$, number of subjects NA, not applicable.

(V.21.0; SPSS). Two-tailed $\mathrm{p}$ values of $<0.05$ were considered significant.

\section{RESULTS}

Table 1 shows the subjects' characteristics. Compared with non-submariners, submariners were significantly older, were more likely to be current smokers and obese, and had a higher naval rank $(\mathrm{p}<0.05)$. Table 2 shows the distributions of chronic health problems and CIRS scores among all subjects and in the three age strata. The prevalence of multimorbidity was $11.7 \%$ among non-submariners and $32.2 \%$ among submariners. The prevalence of multimorbidity and the CIRS scores gradually increased with age among both submariners and non-submariners. The number of chronic health problems and CIRS scores were significantly higher among submariners than non-submariners, across all age groups.

Table 3 shows the adjusted associations of submarine service with risks of multimorbidity and high disease burden (CIRS of $\geq 3$ ). Submarine service of 1 year or longer was positively associated with multimorbidity and disease burden as compared with less than 1 year of submarine service. This association remained significant after adjusting for age, alcohol consumption, smoking status and naval rank. However, a dose-response relationship according to duration of submarine service was not evident (see online supplementary table S1).

\section{DISCUSSION}

This study is the first to examine the prevalence of multimorbidity and disease burden among submariners. Use of the CIRS score allowed us to provide more comprehensive data, especially regarding the disease burden, compared with previous studies. ${ }^{3} 23$ Based on our findings, approximately $30 \%$ of submariners had multimorbidity, and this rate was approximately three times greater than the prevalence among non-submariner naval personnel $(11.7 \%)$. The higher rate of multimorbidity among submariners was consistently observed in different age strata, which suggests that the significant difference in the multimorbidity rate was not caused by different age distributions.

A previous study in primary care setting has shown that prevalence of multimorbidity might be comparable between studies when multimorbidity is defined as $\geq 2$ disease entities, regardless of the specific disease entity definitions in each study. ${ }^{24}$ The prevalence of multimorbidity varies according to study. After excluding elderly subjects (to simplify the age-based comparisons), we found that the prevalence of multimorbidity among nonsubmariners was $11.7 \%$, which was lower than the reported prevalence in the Netherlands $(24.2 \%$ among men aged 20-59years from the general population), ${ }^{23}$ Scotland (20.5\% among men aged 25-65years from the general population) ${ }^{8}$ and Canada (20.4\% among men aged 18-64years from the general population). ${ }^{25}$ However, the difference in the prevalence of multimorbidity across studies might have been a result of the varying definitions and methods for assessing multimorbidity, as well as the study settings.

In this study, submariners more frequently experienced symptoms in the vascular, respiratory, endocrine and ear/ nose/throat CIRS domains than non-submariners (see online supplementary table S2). This finding is partially consistent with the findings of a previous study, which revealed that respiratory infections and elevated blood pressure without a hypertension diagnosis were common morbidities among American submariners. ${ }^{26}$ We assume that our findings may be related to the fact that current 
smoking and obesity are counted as respiratory and endocrine diseases, respectively, in the CIRS system. ${ }^{18}$ Although the smoking rate was lower in submariners than in non-submariners, worse air quality from the enclosed space of a submarine might have contributed to the more prevalent respiratory and ear/nose/throat symptoms.

We observed positive associations between age and multimorbidity among both non-submariners and submariners, and this association has been clearly documented in previous studies. ${ }^{6823}$ In addition, our finding of increasing disease burden (estimated using CIRS) with age was similar to the findings from a Canadian study. ${ }^{21}$ However, submariners had a greater prevalence of multimorbidity and greater disease burden in all age groups, compared with non-submariners. Although the current smoking rate among submariners was comparable to that among the general population of Korean men $(47 \%$ in 2012), ${ }^{27}$ the higher smoking rate among submariners may explain their greater disease burden, as current smoking is considered a respiratory problem in the CIRS system. In addition, the submariners' obesity rate was higher than that among Korean non-submariners, American small submarine crews ( $17.9 \%$ in 2011) ${ }^{28}$ and American police officers and firefighters (30.7\% in 2002), ${ }^{29}$ which may also explain the difference in disease burden. Although different cut-off values for obesity are used for Korean and American populations ( $\left.\geq 25 \mathrm{~kg} / \mathrm{m}^{2} \mathrm{vs} \geq 30 \mathrm{~kg} / \mathrm{m}^{2}\right)$, we think the results are comparable in terms of obesity diagnoses because Asian populations have a higher body fat composition for any given BMI than Caucasian populations ${ }^{30}$ and increased all-cause mortality is associated with BMI of $\geq 25 \mathrm{~kg} / \mathrm{m}^{2}$ in the Korean population. ${ }^{31}$

Unfortunately, the confined submarine environment is not conducive to vigorous activity and exercise during deployment, ${ }^{32}$ and submariners' caloric intake tends to exceed their expenditure during this time. ${ }^{12}$ Moreover, submariners' shift work schedules during their deployment may increase their risk of metabolic syndrome. ${ }^{33}$ Thus, the combination of low physical activity levels, excessive caloric intake and circadian misalignment may elevate the risk of accumulating abdominal and visceral fat, ${ }^{34}$ which could explain the prevalence of obesity among submariners. These factors may also have contributed to the high disease burden and prevalence of multimorbidity among submariners, compared with non-submariners.

As age is strongly associated with multimorbidity, ${ }^{82}$ it is possible that the association between multimorbidity and service years was confounded by age. However, after adjusting for age, the positive associations of submarine service with multimorbidity as well as disease burden were only slightly attenuated. Thus, our findings negate a significant confounding effect of age on the association.

Submariners are exposed to several health risk factors, such as $H$. pylori infection, that are related to overcrowding and extremely limited sanitary facilities, ${ }^{15}$ increased cortisol levels related to chronic stress state and sleep deprivation, ${ }^{35}$ and low air quality in an enclosed 
Table 3 Association of submarine service with the risk of multimorbidity ${ }^{\star}$ and high disease burden $\dagger$

Years of submarine service

\begin{tabular}{|c|c|c|c|c|c|}
\hline & \multicolumn{4}{|c|}{ rears or suomarme service } & $\mathrm{p}$ Trend $\neq$ \\
\hline \multicolumn{6}{|c|}{ OR $(95 \% \mathrm{Cl}) \S$ for the association with multimorbidity * } \\
\hline Model 1 & 1 & $3.46(1.75-6.87)$ & $2.59(1.37-4.89)$ & $3.97(2.19-7.19)$ & $<0.001$ \\
\hline Model 2 & 1 & $3.97(1.91-8.25)$ & $2.75(1.41-5.38)$ & $3.78(2.06-6.94)$ & $<0.001$ \\
\hline \multicolumn{6}{|c|}{ OR $(95 \% \mathrm{CI}) \S$ for the association with the high disease burden† estimated by Cumulative IIIness Rating Scale } \\
\hline Model 1 & 1 & $1.86(1.04-3.32)$ & $2.36(1.37-4.05)$ & $2.77(1.63-4.71)$ & 0.001 \\
\hline
\end{tabular}

*Defined as two or more chronic health problems in a person.

†Defined as Cumulative Illness Rating Scale score $\geq 3$.

$\ddagger$ Assessed by linear regression analysis, with years of service as a continuous variable.

§Estimated by multiple logistic regression analysis. In model 1, age was adjusted. In model 2, age, alcohol intake, smoking status (not included in the analysis for the disease burden) and job ranking were adjusted.

space. ${ }^{36}$ These risk factors may have cumulative negative effects on submariners' health status, which might partially explain the higher prevalence of multimorbidity in this population. Nevertheless, previous studies have reported conflicting findings regarding the health of submariners. For example, a study by the American Navy revealed that submarine duty did not increase the risk of hospitalisation for 16 major diagnostic categories and submarine-associated diagnoses. ${ }^{37}$ However, we could not directly compare the findings of that study and our study, as we used different methods to identify morbidities (outpatient clinical records vs hospitalisation records and multimorbidity vs single disease entities).

Few studies have evaluated the risk of mortality among submariners, and those studies have reported no significant association. A British study of Royal Navy submarine crews concluded that working in a submarine was not associated with increased cancer mortality, although the authors detected an increase in liver cirrhosis-related mortality that might not be attributable to the submarine environment. ${ }^{16}$ A Norwegian study also failed to detect differences in all-cause mortality among surface vessel and submarine crews, and the submariners had a lower rate of all-cause mortality than the general population of Norwegian men. ${ }^{14}$ Several explanations were proposed for the null finding from the Norwegian study. First, the participants had relatively low mean service times (2.7 years), which may have been insufficient to noticeably affect the subjects' mortality. Another plausible explanation is that morbidity may not significantly affect mortality in a relatively young and healthy population, unlike older populations. ${ }^{3}$ Furthermore, the 'healthy soldier effect' may result in submariners having a good initial health state, as military personnel and submariners are specially selected to perform challenging tasks, which could diminish the adverse effects of the submarine working environment. ${ }^{10}$

There are several limitations to this study. First, the cross-sectional design precludes any conclusions regarding the causality of the relationship between submarine service and risk of multimorbidity. However, it seems logical to assume that submarine work increases multimorbidity, rather than vice versa, because it is very unlikely that multimorbidity would drive an individual to submarine work. Second, the absence of a standardised definition led us to create our own arbitrary definition for multimorbidity ( $\geq 2$ coexisting chronic conditions in a single patient), and it is possible that we underestimated or overestimated the prevalence of multimorbidity. Third, selection bias is possible, as it was not possible to blind the physicians to each subject's status as a submariner or non-submariner. In addition, subjects who visited the clinic may have had relatively poor health status compared with other naval personnel who did not seek medical attention. Fourth, the specificity of our study population (Korean submariners) and the absence of an age-matched non-navy personnel control group may limit the generalisation of our findings to other populations.

In conclusion, this Korean study revealed that, compared with non-submarine service, submarine service was significantly associated with a higher risk of multimorbidity and greater disease burden, even after adjusting for relevant covariates. These findings suggest that scrupulous attention is needed to assess submariners and manage their health conditions in multidimensional and holistic ways. Further research is needed to examine the effects of multimorbidity on disease patterns, quality of life and overall mortality among submariners.

Contributors Jihun Kang contributed to building the conception and design of the work, data collection, analysing and interpretation of data and drafting and revising the article. Yun-Mi Song contributed to building the conception and design of the work, analysing and interpretation of data, clarifying important intellectual content of the result and critical revision from draft version to final version of the article. Both authors participated in final approval of the version to be published and contributed to ensuring that questions related to the accuracy or integrity of any part of the work are appropriately investigated and resolved.

Funding This study was supported by funding from the Armed Forces Medical Command, South Korea.

Competing interests None declared.

Patient consent Obtained.

Ethics approval Institutional Review Board of the Armed Forces Medical Command in Seongnam, South Korea (AFMC-15088-IRB-15-068).

Provenance and peer review Not commissioned; externally peer reviewed. 
Data sharing statement Access to the dataset used in this study is restricted by Ministry of National Defense, Republic of Korea.

Open Access This is an Open Access article distributed in accordance with the Creative Commons Attribution Non Commercial (CC BY-NC 4.0) license, which permits others to distribute, remix, adapt, build upon this work non-commercially, and license their derivative works on different terms, provided the original work is properly cited and the use is non-commercial. See: http://creativecommons.org/ licenses/by-nc/4.0/

(c) Article author(s) (or their employer(s) unless otherwise stated in the text of the article) 2017. All rights reserved. No commercial use is permitted unless otherwise expressly granted.

\section{REFERENCES}

1. Glynn LG, Valderas JM, Healy P, et al. The prevalence of multimorbidity in primary care and its effect on health care utilization and cost. Fam Pract 2011;28:516-23.

2. Fortin M, Bravo G, Hudon C, et al. Relationship between multimorbidity and health-related quality of life of patients in primary care. Qual Life Res 2006;15:83-91.

3. Menotti A, Mulder I, Nissinen A, et al. Prevalence of morbidity and multimorbidity in elderly male populations and their impact on 10year all-cause mortality: The FINE study (Finland, Italy, Netherlands, Elderly). J Clin Epidemiol 2001;54:680-6.

4. Organization WHO. World health statistics 2010: World Health Organization, 2010.

5. van den Akker M, Buntinx F, Knottnerus JA. Comorbidity or multimorbidity: what's in a name? A review of literature. The European Journal of General Practice 1996;2:65-70.

6. Marengoni A, Angleman S, Melis R, et al. Aging with multimorbidity: a systematic review of the literature. Ageing Res Rev 2011;10:430-9.

7. Taylor AW, Price K, Gill TK, et al. Multimorbidity - not just an older person's issue. Results from an Australian biomedical study. BMC Public Health 2010;10:1.

8. Barnett K, Mercer SW, Norbury M, et al. Epidemiology of multimorbidity and implications for health care, research, and medical education: a cross-sectional study. Lancet 2012;380:37-43.

9. Prados-Torres A, Poblador-Plou B, Calderón-Larrañaga A, et al. Multimorbidity patterns in primary care: interactions among chronic diseases using factor analysis. PLoS One 2012;7:e32190.

10. McLaughlin R, Nielsen L, Waller M. An evaluation of the effect of military service on mortality: quantifying the healthy soldier effect. Ann Epidemiol 2008;18:928-36.

11. Brasher KS, Dew AB, Kilminster SG, et al. Occupational stress in submariners: the impact of isolated and confined work on psychological well-being. Ergonomics 2010;53:305-13.

12. Hartwell J, Durocher N, Gertner J, et al. A comparison of the prevalence of metabolic syndrome among fast-attack submariners with us civilian males. 2009.

13. Sandal GM, Leon G, Palinkas L. Human challenges in polar and space environments. Life in Extreme Environments. 2007399-414.

14. Strand LA, Martinsen JI, Koefoed VF, et al. Cause-specific mortality and cancer incidence among 28,300 Royal Norwegian Navy servicemen followed for more than 50 years. Scand J Work Environ Health 2011;37:307-15.
15. Hammermeister I, Janus G, Schamarowski F, et al. Elevated risk of Helicobacter pylori infection in submarine crews. Eur J Clin Microbiol Infect Dis 1992;11:9-14.

16. Inskip $H$, Snee M, Styles L. The mortality of Royal Naval submariners 1960-89. Occup Environ Med 1997;54:209-15.

17. Oh SW, Sw O. Obesity and metabolic syndrome in Korea. Diabetes Metab J 2011;35:561-6.

18. Hudon $\mathrm{C}$, Fortin $\mathrm{M}$, Soubhi $\mathrm{H}$. Abbreviated guidelines for scoring the Cumulative Illness Rating Scale (CIRS) in family practice. J Clin Epidemiol 2007;60:e1-. e4.:212.e1-212.e4.

19. Linn BS, Linn MW, Gurel L. Cumulative illness rating scale. J Am Geriatr Soc 1968;16:622-6.

20. Miller MD, Paradis CF, Houck PR, et al. Rating chronic medical illness burden in geropsychiatric practice and research: application of the Cumulative IIIness Rating Scale. Psychiatry Res 1992;41:237-48.

21. Fortin M, Bravo G, Hudon C, et al. Prevalence of multimorbidity among adults seen in family practice. Ann Fam Med 2005;3:223-8.

22. Hudon C, Fortin M, Vanasse A. Cumulative Illness Rating Scale was a reliable and valid index in a family practice context. J Clin Epidemiol 2005;58:603-8.

23. van den Akker M, Buntinx F, Metsemakers JF, et al. Multimorbidity in general practice: prevalence, incidence, and determinants of co-occurring chronic and recurrent diseases. J Clin Epidemiol 1998;51:367-75.

24. Harrison $\mathrm{C}$, Britt $\mathrm{H}$, Miller $\mathrm{G}$, et al. Examining different measures of multimorbidity, using a large prospective cross-sectional study in Australian general practice. BMJ Open 2014;4:e004694.

25. Agborsangaya CB, Lau D, Lahtinen M, et al. Multimorbidity prevalence and patterns across socioeconomic determinants: a cross-sectional survey. BMC Public Health 2012;12:1.

26. Jan M, Thomas T, Hooper T. Prescription medication use aboard US submarines during periods underway.. 2002.

27. Jee SH, Samet JM, Ohrr H, et al. Smoking and cancer risk in Korean men and women. Cancer Causes Control 2004;15:341-8.

28. Gregg MA, Jankosky CJ. Physical readiness and obesity among male U.S. Navy personnel with limited exercise availability while at sea. Mil Med 2012;177:1302-7.

29. Caban AJ, Lee DJ, Fleming LE, et al. Obesity in US workers: The National Health Interview Survey, 1986 to 2002. Am J Public Health 2005:95:1614-22.

30. Deurenberg P, Yap M, van Staveren WA. Body mass index and percent body fat: a meta analysis among different ethnic groups. Int J Obes Relat Metab Disord 1998;22:1164-71.

31. Jee SH, Sull JW, Park J, et al. Body-mass index and mortality in Korean men and women. N Engl J Med 2006;355:779-87.

32. Choi SW, Lee JH, Jang YK, et al. Assessment of ambulatory activity in the Republic of Korea Navy submarine crew. Undersea Hyperb Med 2010;37:413.

33. De Bacquer D, Van Risseghem M, Clays E, et al. Rotating shift work and the metabolic syndrome: a prospective study. Int $\mathrm{J}$ Epidemiol 2009;38:848-54.

34. Ross R, Janssen I. Physical activity, total and regional obesity: doseresponse considerations. Med Sci Sports Exerc 2001;33:S521-S527. discussion S8-9.

35. Reini SA. Hypercortisolism as a potential concern for submariners. Aviat Space Environ Med 2010;81:1114-22.

36. Hocking MB, Hocking D. Air quality in airplane cabins and similar enclosed spaces: Springer Science \& Business Media, 2005.

37. Burr SH, Palinkas RG, Lawrence A. Health risks among submarine personnel in the US Navy, 1974-1979. DTIC Document 1986. 